\title{
Fundamental and higher-mode Rayleigh wave characteristics of ambient seismic noise in New Zealand
}

\author{
Laura A. Brooks, ${ }^{1}$ John Townend, ${ }^{1}$ Peter Gerstoft, ${ }^{2}$ Stephen Bannister, ${ }^{3}$ and Lionel Carter ${ }^{4}$ \\ Received 6 August 2009; revised 19 October 2009; accepted 26 October 2009; published 2 December 2009.
}

[1] In order to use ambient seismic noise for mapping Earth's structure, it is important to understand the spatiotemporal characteristics of the noise field. This study uses data collected during four austral winter months of 2002 to investigate New Zealand's ambient seismic noise field in the double-ocean-wave-frequency range $(0.1-0.3 \mathrm{~Hz})$. It is shown via beamforming analysis that there are two distinct dispersive waves in the data. These waves can be separated. Their estimated phase velocities $(2.5-2$ and $4-3 \mathrm{~km} / \mathrm{s}$ in the frequency range $0.14-0.25 \mathrm{~Hz}$ ) match well with fundamental and higher-mode Rayleigh dispersion curves. Studies of double-wave-frequency microseisms elsewhere generally show the Rayleigh noise fields to be dominated by fundamental mode waves. The reason why higher-mode signals are observed here may reflect a combination of long ocean wave periods, large waveheights, the direct deep water approach to narrow continental margins, and the proximity of the seismograph array to the source regions. Citation: Brooks, L. A., J. Townend, P. Gerstoft, S. Bannister, and L. Carter (2009), Fundamental and higher-mode Rayleigh wave characteristics of ambient seismic noise in New Zealand, Geophys. Res. Lett., 36, L23303, doi:10.1029/2009GL040434.

\section{Introduction}

[2] The ambient seismic noise field is largely dominated by signals with frequencies of $<1 \mathrm{~Hz}$ that correspond to Rayleigh waves produced by nonlinear ocean wave processes [Bromirski and Duennebier, 2002]. The microseism spectrum typically exhibits a small peak at $0.06-0.07 \mathrm{~Hz}$ and a larger peak at $0.12-0.15 \mathrm{~Hz}$, termed the single frequency (SF) and double frequency (DF) microseism peaks, respectively [Webb, 1998]. The SF peak is generally thought to be generated by direct ocean wave-induced pressure fluctuations at the sea floor, the amplitudes of which decrease with ocean depth [Bromirski and Duennebier, 2002]. The DF peak occurs due to non-linear interaction of opposing wavefields of similar wavenumbers [Longuet-Higgins, 1950], which creates an excitation pulse at twice the ocean wave frequency. This propagates almost unattenuated to the seafloor and couples into a Rayleigh wave. The minimal attenuation in the water column means that DF signals represent both shallow and deep water

\footnotetext{
${ }^{1}$ School of Geography, Environment and Earth Sciences, Victoria University of Wellington, Wellington, New Zealand.

${ }^{2}$ Scripps Institution of Oceanography, University of California, San Diego, La Jolla, California, USA.

${ }^{3}$ GNS Science, Lower Hutt, New Zealand.

${ }^{4}$ Antarctic Research Centre, Victoria University of Wellington, Wellington, New Zealand.
}

Copyright 2009 by the American Geophysical Union. 0094-8276/09/2009GL040434 phenomena, though DF signals recorded on land are usually dominated by shallow water excitation [Tanimoto, 2007].

[3] New Zealand's geographic isolation and $\sim 15,000 \mathrm{~km}-$ long coastline expose it to a particularly energetic ocean, producing a high-amplitude seismic noise field [Pickrill and Mitchell, 1979; Gorman et al., 2003], and several New Zealand noise studies relating ambient noise spectra/ amplitudes to wave spectra/heights have been conducted previously [Kibblewhite and Ewans, 1985; Tindle and Murphy, 1999]. The energetic noise field makes the New Zealand region a suitable location for using ambient seismic noise for seismic tomography studies [Lin et al., 2007]; however, the long coastline and complex ocean regime that generate this noise field also result in more complex spatial and temporal noise distributions than may be observed in many other regions (e.g., continental USA). To further increase the accuracy of geophysical estimates using ambient noise in New Zealand, a greater understanding of the spatio-temporal noise characteristics is needed (Y. Behr et al., Shear-velocity structure of the Northland Peninsula, New Zealand, inferred from ambient noise correlations, submitted to Journal of Geophysical Research, 2009).

[4] Results from beamforming of microseismic data using seismic arrays have been reported elsewhere [e.g., Haubrich and McCamy, 1969; Chevrot et al., 2007; Gerstoft et al., 2008], but not in New Zealand. Here we employ frequencydomain beamforming of vertical-component data from a seismograph array located in the Taranaki region, western North Island (see Figure 1), to determine the locations of microseism generation. We compare our results to shallow water wave heights (supplied by the National Institute of Water and Atmospheric Research from their wave prediction model, NIWAM). Two distinctive dispersive waves, namely fundamental and higher-mode Rayleigh waves, are observed in the beamformed data. This result differs from those of other studies of double-wave-frequency microseisms, which have shown the noise field to be dominated by a single mode, namely fundamental mode Rayleigh waves [Lacoss et al., 1969; Tanimoto and Alvizuri, 2006]. The dominant source regions of the two signals we observe are interpreted with reference to New Zealand's oceanographic conditions.

\section{Data Processing}

[5] The seismic data analyzed here were recorded in the austral winter months of May-August, 2002, on the verticalcomponents of a 61-element broadband three-component seismograph array located in the Taranaki region (Figure 1) [Sherburn and White, 2005]. Useful data were obtained from 50-58 seismographs at any one time.

[6] Day-long seismic traces recorded at $5 \mathrm{~Hz}$ were bandpass filtered to $0.02-0.4 \mathrm{~Hz}$ and downsampled to $1 \mathrm{~Hz}$. The 

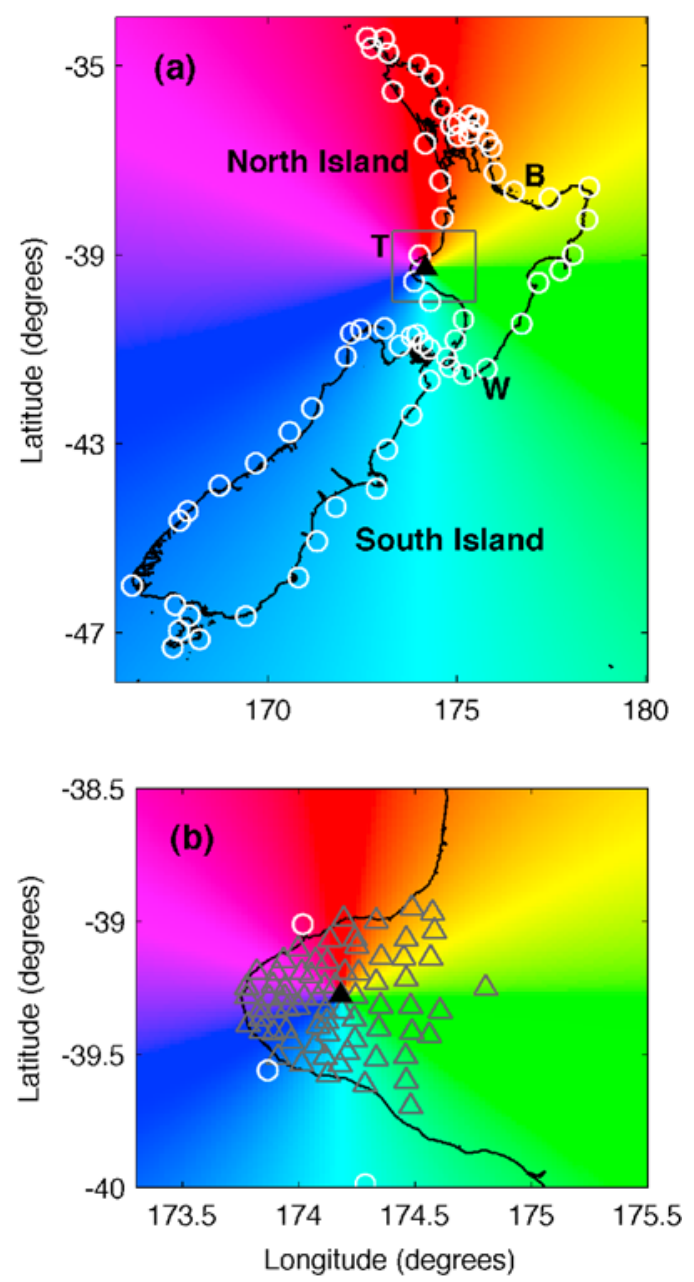

Figure 1. Map of (a) New Zealand and (b) Taranaki region showing the seismic array center location (black triangle), individual seismic stations (gray triangles), and locations along New Zealand's $50 \mathrm{~m}$ isobath at which NIWAM model wave statistics were extracted (white circles). The letters ' $\mathrm{B}$ ', ' $\mathrm{T}$ ' and ' $\mathrm{W}$ ' denote the Bay of Plenty, the Taranaki region, and the Wairarapa region, respectively. The color map denotes the azimuth from the array center.

data were separated into 3-hour long segments and clipped to half their standard deviation. The data were split into 1024-s long time series and Fourier transformed, giving a collection of short-time transforms across the array. In order to retain only the phase, the signals within each frequency band were normalized by their amplitudes. The frequency and time domain normalizations reduce the effect of episodic processes [Gerstoft et al., 2008]. All stations had the same nominal response and hence station response corrections were not made.

[7] Plane wave frequency domain beamforming was implemented following the methodology of Johnson and Dudgeon [1993]:

[8] 1. We first calculated the vector of amplitudenormalized short-time Fourier transforms at $M$ stations $\left(\mathbf{Y}(t, \omega)=\left[\mathbf{Y}_{1}(t, \omega), \cdots, \mathbf{Y}_{M}(t, \omega)\right]^{T}\right.$, where $t$ is time, and $\omega$ is angular frequency).
[9] 2. The spatial correlation matrix, $\mathbf{R}=\left\langle\mathbf{Y} \mathbf{Y}^{\prime}\right\rangle$ was constructed. The temporal averaging was over 3 hours, corresponding to the period of the NIWAM model statistics.

[10] 3. We next calculated the array plane wave response, $\mathbf{e}=\left[\exp \left(-j \vec{k} \cdot \vec{x}_{1}, \cdots,-j \vec{k} \cdot \vec{x}_{M}\right)\right]^{T}$, where $\vec{x}_{m}$ is the vector defining the location of the $m$ th sensor relative to the array center, $\vec{k}=\vec{\xi} \omega / c$ is the wavenumber vector, and $\vec{\xi}$ the unit vector from the source to the array center.

[11] 4. Finally, we calculated the beamformed outputs, $b(\omega, t, \theta, c)=\mathbf{e}^{\prime} \mathbf{R e}$, where the look direction $\theta$ is antiparallel to the unit vector $\vec{\xi}$, and summed these results across a $0.01 \mathrm{~Hz}$ bandwidth.

[12] The array plane-wave response was analyzed for various propagation angles and frequencies within the bandwidth of interest. An example of a typical response is that of a $0.16 \mathrm{~Hz}$ signal propagating from $180^{\circ}$ at $2.5 \mathrm{~km} / \mathrm{s}$, for which the main lobe $3 \mathrm{~dB}$ bandwidth was calculated to be $0.45 \mathrm{~km} / \mathrm{s}$ and $11^{\circ}$. Side-lobe amplitudes were all significantly lower amplitude $(>10 \mathrm{~dB}$ less) than the main lobe, suggesting a resilience to incorrect source azimuth estimates.

\section{Beamformer Outputs}

[13] Figures $2 \mathrm{a}-2 \mathrm{c}$ show beamformer outputs at three frequencies for one hour's data in mid-July. A strong signal with a phase velocity of between 2 and $3 \mathrm{~km} / \mathrm{s}$, originally at azimuths of $225-270^{\circ}$, and higher-velocity $(>3 \mathrm{~km} / \mathrm{s})$ signals at a range of azimuths are observed (Figures 2a, $2 b$, and $2 c$, respectively). In both the lower- and highervelocity cases, the phase velocities decrease slightly with increasing frequency, suggesting that the signals are dispersive (see section 4).

[14] The phase velocities and azimuths corresponding to the maximum beamformer output are plotted as functions of time and frequency for July in Figures $2 \mathrm{~d}$ and $2 \mathrm{e}$. Two distinct dispersive signals are observed: signals with phase velocities $<3 \mathrm{~km} / \mathrm{s}$ at $0.11-0.19 \mathrm{~Hz}$, and signals with phase velocities $>3 \mathrm{~km} / \mathrm{s}$ at $\sim 0.15-0.25 \mathrm{~Hz}$ (Figure $2 \mathrm{~d}$ ).

[15] Normalized waveheights from the NIWAM model for the $50 \mathrm{~m}$ isobath locations are shown in Figure $2 \mathrm{f}$. The mean of each trace is zeroed on the azimuth of the wave site location relative to the array center, with colors matching the azimuths of Figures 1 and 2e. The $50 \mathrm{~m}$ isobath was chosen as a reasonable depth at which high amplitude microseism excitation would be expected, though depths may actually be significantly greater than this since New Zealand has deeper waters adjacent to the coast and longer period waves than many other regions [Gorman et al., 2003]. Similar wave characteristics would still be expected at each azimuth if the excitation depth were greater.

[16] Signals at azimuths corresponding to the peak beamformer output (Figure 2d) are generally observed within a day of large waveheights (Figure 2f) occur at these azimuths (the delay is likely due to ocean wave dispersion). For example, large waves are observed at an azimuth of $65^{\circ}$ (yellow-orange) on July 12-14, and the beamformer peaks at $65^{\circ}$ on July $13-14$. Mean waveheights in the westerly quadrant (blue-pink) are higher than waveheights originating from other directions (Figure $2 \mathrm{f}$, right). This also agrees well with the observed SW to NW dominance (Figure 2e). 

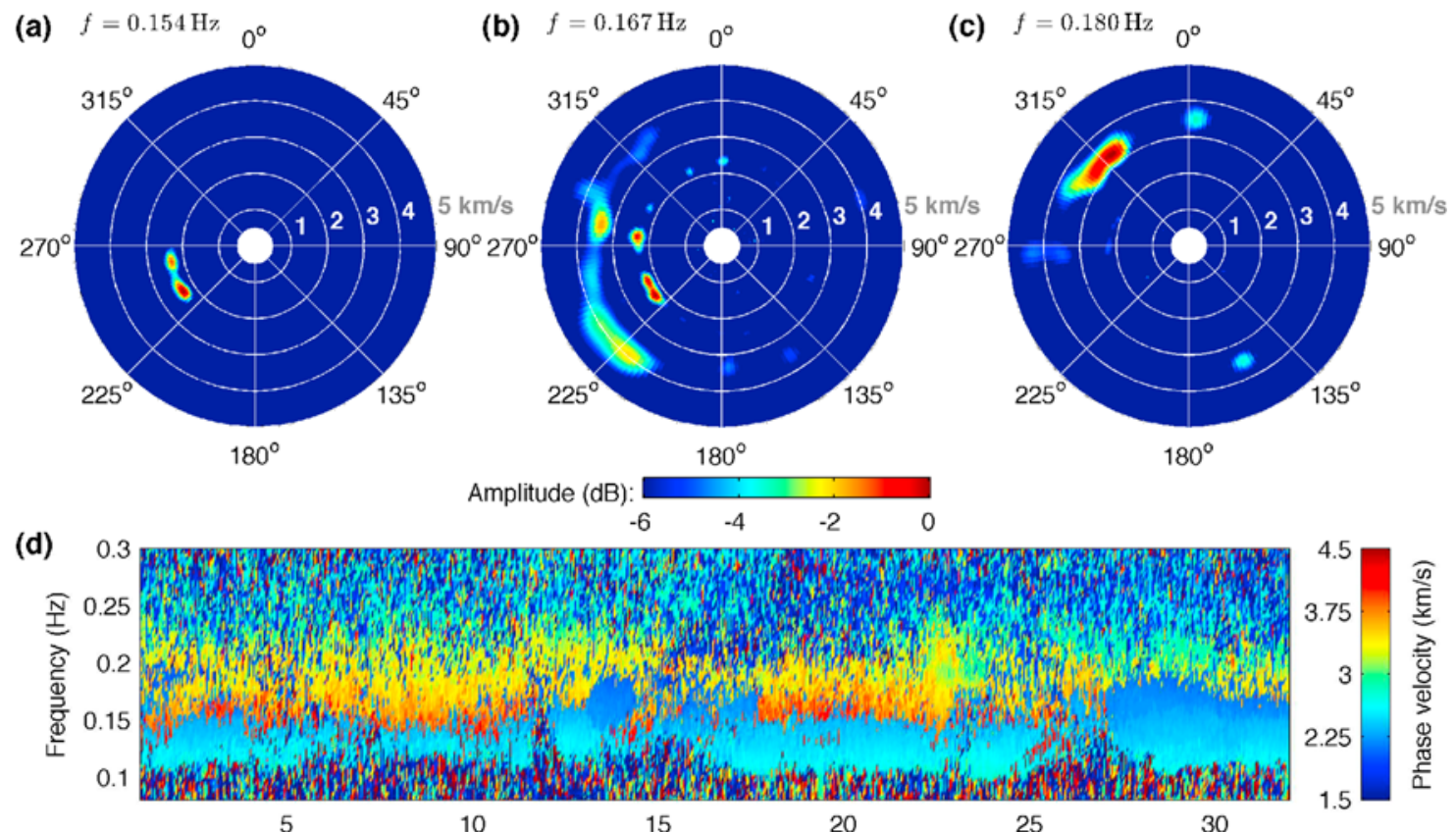

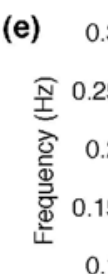
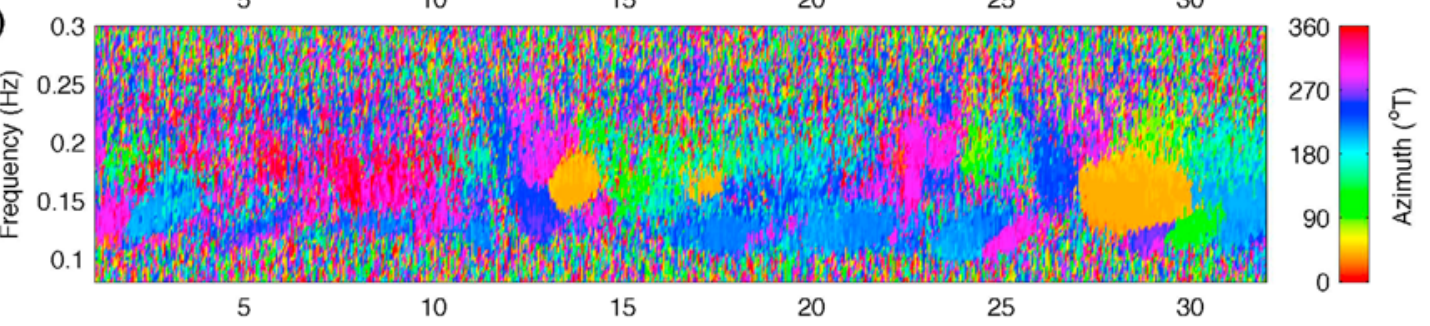

(f)

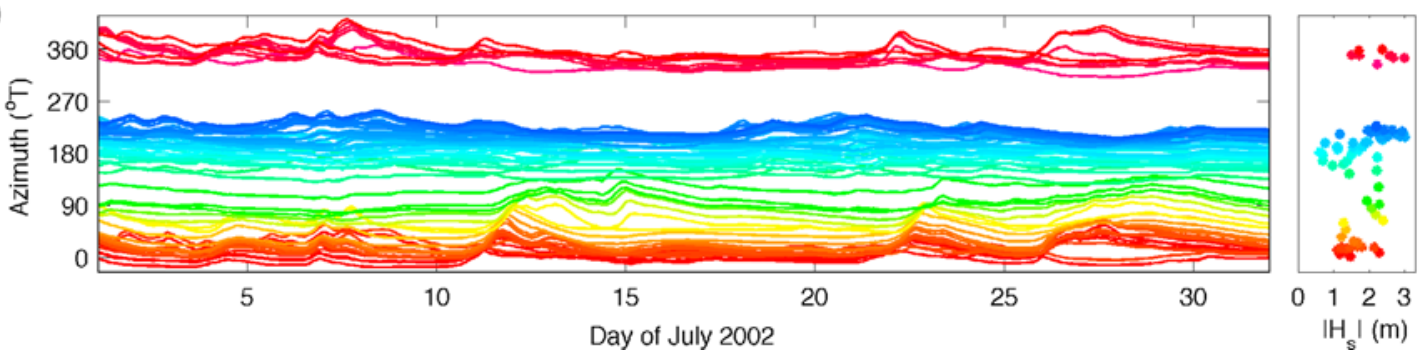

Figure 2. Beamformer outputs at (a) 0.154, (b) 0.167, and (c) 0.180 Hz from 22:00-23:00 July 12. The angular and radial axes are source azimuth from the array center and seismic phase velocity $(\mathrm{km} / \mathrm{s})$, respectively. (d) Azimuths and (e) phase velocities corresponding to the maximum beamformer outputs as a function of frequency throughout July. (f) The waveheights at each NIWAM model data location circled in Figure 1 for July, along with the mean waveheight, $\left|H_{s}\right|$, at each location (far right panel).

[17] Low-frequency signals $(0.1-0.15 \mathrm{~Hz})$, in particular those from the $\mathrm{N}-\mathrm{W}$ quadrant, show clear striations in Figure 2e, with higher frequencies arriving later than low frequencies at several occasions. The slope of a striation, which is due to ocean wave dispersion, can be used to estimate a distance from the location of microseism generation to the storm which creates the ocean waves [Gerstoft and Tanimoto, 2007]. For example, the pink striation of day 25 has a slope of $35 \mathrm{day} / \mathrm{Hz}$, suggesting a distance to the storm of $\approx 3500 \mathrm{~km}$, which is consistent with storms originating in the Southern Ocean [e.g., Kibblewhite et al., 1982].

\section{Dispersion Curves}

[18] To further examine the two dispersive signals in Figure 2d, the beamformer outputs for each of these were separated. This was done by designating all beamformer outputs with velocities above $4.5-(25 / 3) f(f$ is frequency in $\mathrm{Hz}$ ) as higher-velocity signals, and below as lowervelocity signals. The phase velocities and azimuths corresponding to the maximum beamformer output for each case were calculated. Velocities and azimuths corresponding to low-amplitude beamformer outputs (noise) were then removed from the data (the resulting azimuths are shown in Figures $3 \mathrm{a}$ and $3 \mathrm{~b}$ ).

[19] Although the source azimuths of the lower- and higher-velocity signals generally differ (Figures $3 a$ and $3 b$ ), there are some similarities, particularly at low frequencies (e.g., the striations discussed in section 3), suggesting that some lower- and higher-velocity signals are being generated from the same region at the same time.

[20] Median velocities for each month, calculated at each frequency from the beamformed data, are plotted as a function of frequency in Figure 3c. The same line type is 
(a) Lower velocity

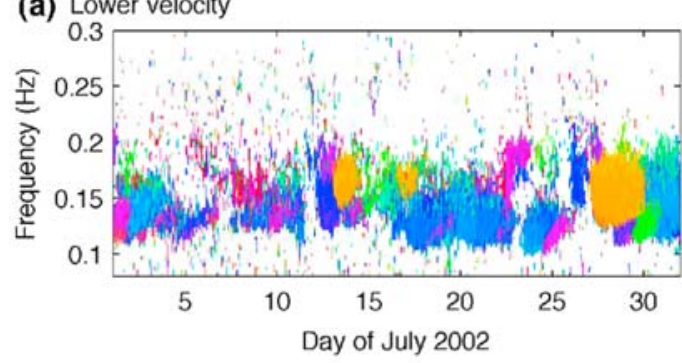

(b) Higher velocity

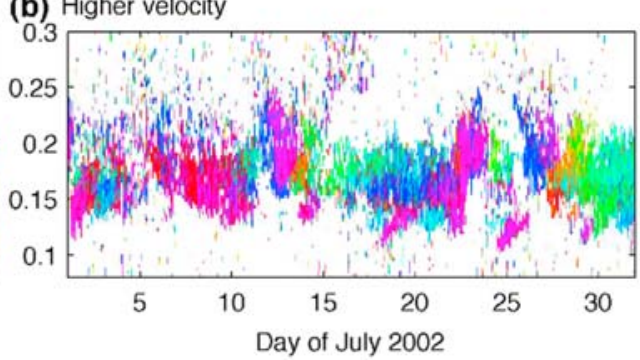

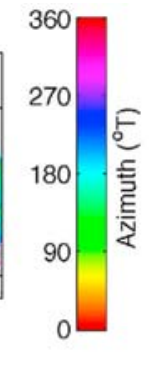

(c) Dispersion curves

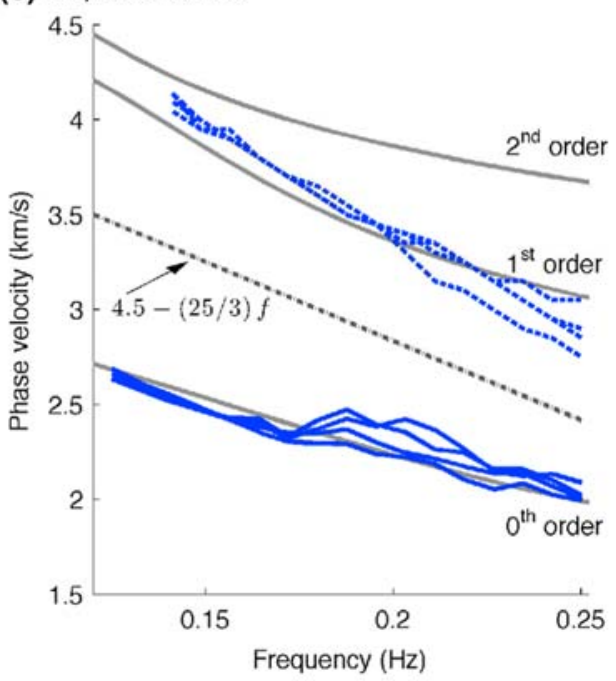

(d) Lower velocity

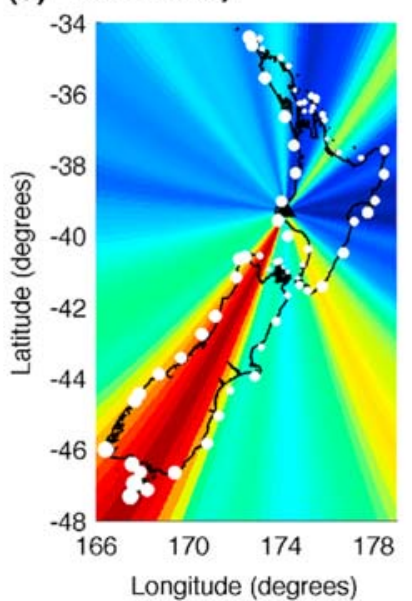

(e) Higher velocity

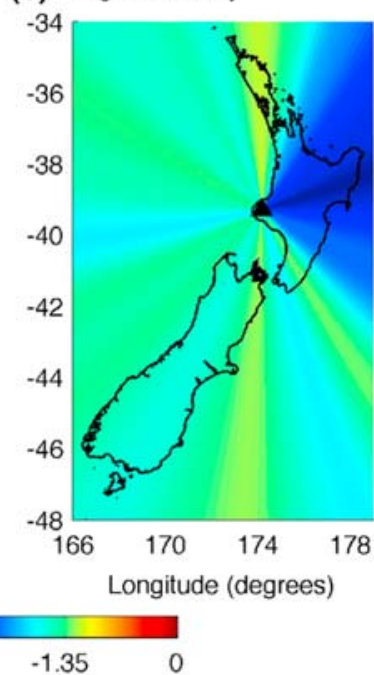

Figure 3. Azimuth of the highest-amplitude (a) lower- and (b) higher-velocity signals for July. (c) Median velocities from beamformed output (solid is lower-velocity and dashed is higher-velocity signal) shown for each of the months April-July (same line style for all months), overlying estimates of the 0th-, 1st-, and 2nd-order mode Rayleigh wave dispersion curves. The equation used to separate the signals (dashed) is shown also. Mean amplitude of beamformer output (jointly normalized to maximum) for the four month period shown as a function of azimuth for the (d) lower- and (e) highervelocity signals at 0.16 and $0.19 \mathrm{~Hz}$, respectively. The white circles shown at each NIWAM model location (see Figure 1) in Figure $3 \mathrm{~d}$ are sized relative to the mean wave height at that location over the four month period.

used for all months since the month-to-month variations are small. Theoretical estimates of the 0th- (fundamental), 1st-, and 2nd-order mode Rayleigh wave dispersion curves are shown for comparison. These dispersion curves were computed assuming the Taranaki region $V_{P}$ and $V_{S}$ models of Sherburn and White [2005], and empirical densities calculated from $\rho=0.23 V_{P}^{0.25}$ [Gardner et al., 1974]. The density had only a small effect on the dispersion curve estimates (e.g., a constant density model of $2.85 \mathrm{~g} / \mathrm{cm}^{3}$ affects the curves by $<3.8 \%$ within our frequency range). The median velocities from the beamformed data show excellent agreement with the theoretical fundamental mode and reasonable agreement to the first-order mode Rayleigh dispersion curve estimates. Discrepancies between the higher-velocity results and the computed dispersion curves may be (i) due to inaccuracies in the modeled $V_{P}$ and $V_{S}$ estimates, or (ii) because the observed higher-mode signal may constitute a complex interaction of several modes with a first-order dominance, rather than a pure first-order mode signal.

\section{Dominant Source Azimuths}

[21] The dominant source azimuths differ substantially between modes and with time (Figures $3 a$ and $3 b$ ). The overall dominant azimuths were investigated by calculating the mean beamformer output (normalized to maximum) over the four month period of the fundamental Rayleigh signal at $0.16 \mathrm{~Hz}$ (Figure 3d), and the higher-mode Rayleigh signal at $0.19 \mathrm{~Hz}$ (Figure 3e), each calculated at the mean phase velocity for that frequency.

[22] Dominant source regions of the fundamental signals (Figure 3d) are southernmost New Zealand, the Wairarapa coast and Bay of Plenty (both labeled in Figure 1). These regions have in common deep water waves that progress onto a narrow continental shelf backed by a linear or semilinear coast. Ocean wave attenuation is thus minimized, enhancing the potential for standing waves. The highermode signals (Figure 3e) do not exhibit such dominance from any one azimuth or region. Higher amplitudes are seen in an arc running from $\mathrm{N}$ to $\mathrm{W}$ to $\mathrm{SE}$.

\section{Discussion}

[23] This analysis provides new insight into the spatiotemporal characteristics of the New Zealand noise field. Of particular interest is the discovery of two separate dispersive signals; a lower-velocity signal with dispersion characteristics that match fundamental mode Rayleigh waves, and a 
higher-velocity signal with dispersion characteristics that agree with first-order mode Rayleigh dispersion curve estimates (with possible interaction of other modes).

[24] The strongest fundamental signal is received from the south where Southern Ocean storms and long fetches generate large swell that progress directly to the narrow continental margin of southernmost New Zealand. Waves typically arrive from WSW to SW, with $>14$ s period swell occurring 30-50\% of the time [Pickrill and Mitchell, 1979]. Mean nearshore waveheights over the study period were the largest in this region (Figure 3d). Microseisms from the Wairarapa are most intense when either eastward-tracking storms from the Tasman Sea impinge on the narrow $(<15 \mathrm{~km})$ Wairarapa shelf, or when Southern Ocean swell moves directly onto the shelf (observed from WAVEWATCH III hindcasts [Tolman, 2002]). ENE swell is prominent in the Bay of Plenty [Gorman et al., 2003] and can have maximum periods of about $16 \mathrm{~s}$ [Pickrill and Mitchell, 1979]. The signals from the Bay of Plenty (Figure 2d) occur shortly after trans-Tasman storms have passed across northern New Zealand (from WAVEWATCH III).

[25] Higher-mode signals from southernmost New Zealand are significantly lower in amplitude than for the fundamental mode. This is possibly because the higher-frequency, highervelocity signals attenuate more over the large distance between source and array. Similarly, the lack of significant signal from the Bay of Plenty could be due to the high attenuation of higher-frequency signals in the Taupo Volcanic Zone (situated between the Bay of Plenty and Taranaki) [Dowrick, 2007].

[26] The dominant periods associated with the highervelocity signals (about $10 \mathrm{~s}$ ) are most likely to be generated by local meteorological disturbances tracking eastward across the Tasman Sea [e.g., Kidson, 2000] or extratropical storms from the north [e.g., Sinclair, 2002]. Such energetic systems may override the prevailing regional swell, which is typified by $12 \mathrm{~s}$ periodicity from distant Southern Ocean sources in the southwest [Kibblewhite et al., 1982].

[27] We have focused on higher-mode microseisms. The reason why higher-mode signals are observed here, and not in many other places subject to beamforming, may reflect the long periods and large waveheights of New Zealand swell, coupled with the presence of deep water approaches to a narrow continental margin. Higher-order-modes have amplitude maxima at greater depths, and therefore this scenario may allow for more energy to be pumped into these modes. Additionally, the relatively close proximity of the seismograph array to the source regions will reduce seismic attenuation.

[28] Acknowledgments. This work was supported by the Royal Society of New Zealand's Marsden fund grant no. VUW0712. The seismic data were downloaded from IRIS Data Management Center and the wave model data were supplied by Richard Gorman, National Institute of Water and Atmospheric Research.

\section{References}

Bromirski, P. D., and F. K. Duennebier (2002), The near-coastal microseism spectrum: Spatial and temporal wave climate relationships, J. Geophys. Res., 107(B8), 2166, doi:10.1029/2001JB000265.

Chevrot, S., M. Sylvander, S. Benahmed, C. Ponsolles, J. M. Lefèvre, and D. Paradis (2007), Source locations of secondary microseisms in western Europe: Evidence for both coastal and pelagic sources, J. Geophys. Res., 112, B11301, doi:10.1029/2007JB005059.

Dowrick, D. (2007), Effects of attenuation in the Taupo Volcanic Zone on patterns of spatial distribution of ground shaking in New Zealand earthquakes, N. Z. J. Geol. Geophys., 50, 315-325.

Gardner, G. H. F., L. W. Gardner, and A. R. Gregory (1974), Formation velocity and density: The diagnostic basics for stratigraphic traps, Geophysics, 39, 770-780.

Gerstoft, P., and T. Tanimoto (2007), A year of microseisms in southern California, Geophys. Res. Lett., 34, L20304, doi:10.1029/2007GL031091.

Gerstoft, P., P. M. Shearer, N. Harmon, and J. Zhang (2008), Global P, PP, and PKP wave microseisms observed from distant storms, Geophys. Res. Lett., 35, L23306, doi:10.1029/2008GL036111.

Gorman, R. M., K. R. Bryan, and A. K. Laing (2003), Wave hindcast for the New Zealand region: Deep-water wave climate, N. Z. J. Mar. Freshwater Res., 37, 589-612.

Haubrich, R. A., and K. McCamy (1969), Microseisms: Coastal and pelagic sources, Bull. Seismol. Soc. Am., 7, 539-571.

Johnson, D. H., and D. E. Dudgeon (1993), Array Signal Processing: Concepts and Techniques, Prentice Hall, Englewood Cliffs, N. J.

Kibblewhite, A. C., and K. C. Ewans (1985), Wave-wave interactions, microseisms, and infrasonic ambient noise in the ocean, J. Acoust. Soc. Am., 78, 981-994.

Kibblewhite, A. C., P. R. Bergquist, B. A. Foster, M. R. Gregory, and M. C. Miller (1982), Maui development environmental study-Report on Phase Two 1977-1981, technical report, Univ. of Auckland, Auckland, N. Z.

Kidson, J. K. (2000), An analysis of New Zealand synoptic types and their use in defining weather regimes, Int. J. Climatol., 20, 299-316.

Lacoss, R. T., E. J. Kelly, and M. N. Toksöz (1969), Estimation of seismic noise structure using arrays, Geophysics, 34, 21-38.

Lin, F., M. H. Ritzwoller, J. Townend, S. Bannister, and M. K. Savage (2007), Ambient noise Rayleigh wave tomography of New Zealand, Geophys. J. Int., 170(2), 649-666.

Longuet-Higgins, M. S. (1950), A theory of the origin of microseisms, Philos. Trans. R. Soc. London, Ser. A, 243, 1-35.

Pickrill, R. A., and J. S. Mitchell (1979), Ocean wave characteristics around New Zealand, N. Z. J. Mar. Freshwater Res., 13, 501-520.

Sherburn, S., and R. S. White (2005), Crustal seismicity in Taranaki, New Zealand using accurate hypocentres from a dense network, Geophys. J. Int., 162, 494-506.

Sinclair, M. R. (2002), Extratropical transition of Southwest Pacific tropical cyclones. Part 1: Climatology and mean structure changes, Mon. Weather Rev., 130, 509-609.

Tanimoto, T. (2007), Excitation of microseisms, Geophys. Res. Lett., 34, L05308, doi:10.1029/2006GL029046.

Tanimoto, T., and C. Alvizuri (2006), Inversion of the HZ ratio of microseisms for S-wave velocity in the crust, Geophys. J. Int., 165, 323-335.

Tindle, C. T., and M. J. Murphy (1999), Microseisms and ocean wave measurements, IEEE J. Oceanic Eng., 24(1), 112-115.

Tolman, H. L. (2002), User manual and system doumentation of WAVEWATCH-III version 2.22, NOAA/NWS/NCEP/OMB Tech. Note 222, NOAA, Silver Spring, Md.

Webb, S. C. (1998), Broadband seismology and noise under the ocean, Rev. Geophys., 36, 105-142.

S. Bannister, GNS Science, PO Box 30-368,1 Fairway Dr., Lower Hutt 6315, New Zealand.

L. A. Brooks and J. Townend, School of Geography, Environment and Earth Sciences, Victoria University of Wellington, PO Box 600, Wellington 6140, New Zealand. (lbrook02@gmail.com)

L. Carter, Antarctic Research Centre, Victoria University of Wellington, PO Box 600, Wellington 6140, New Zealand.

P. Gerstoft, Scripps Institution of Oceanography, University of California, San Diego, 9500 Gilman Dr., La Jolla, CA 92093-0238, USA. 